\title{
КОНКУРЕНТОСПОСОБНОСТЬ ЖЕНЩИН НА РЫНКЕ ТРУДА В СВЕТЕ ГЛОБАЛЬНЫХ ТРЕНДОВ
}

\author{
() 2018 Соболева Ирина Викторовна \\ доктор экономических наук, главный научный сотрудник \\ Институт экономики Российской академии наук \\ 117218, г. Москва, Нахимовский пр., д. 32 \\ E-mail: irasobol@gmail.com
}

В статье рассматриваются факторы и тенденции изменения конкурентоспособности женщин в современной экономике. На основе данных международных исследований показано, что сегодня главные факторы снижающие относительную конкурентоспособность женщин по сравнению с мужчинами связаны не с качеством женской рабочей силы, а с гендерными стереотипами, которые запускают механизмы гендерной дискриминации, тормозящие реализацию человеческого потенциала женщин в сфере занятости.

Ключевые слова: конкурентоспособность женщин, рынок труда, гендерный разрыв, индекс гендерного неравенства, гендерная дискриминация

Существует ряд категорий рабочей силы, которые традиционно считаются обладателями относительно низкой конкурентоспособности на рынке труда. К ним относятся лица старших возрастов, молодежь, впервые выходящая на рынок труда, трудовые мигранты и представители некоренного населения той или иной страны. К этой группе относятся и женщины, как правило, уступающие работникам-мужчинам по ряду основных индикаторов конкурентоспособности.

Индикаторами конкурентоспособности работников могут служить 1) показатели качества рабочей силы, прежде всего образовательные и профессионально-квалификационные характеристики, показатели состояния здоровья, характеризующие индивидуальный человеческий (экономический) потенциал 2) показатели, характеризующие их положение в сфере занятости, т.е. масштабы и успешность фактической реализации этого потенциала в сфере труда. Ко второй группе относятся уровень экономической активности, занятости и безработицы сопоставляемых категорий работников, размер заработной платы, статус рабочего места, режим и условия труда, объем предоставленных работодателем социальных гарантий. На протяжении длительного исторического периода практически во всех странах мира женщины уступали мужчинам по большинству показателей обеих групп. Однако в последние несколько десятилетий прослеживается тенденция к росту человеческого потенциала женщин и к сокращению на этой основе гендерного разрыва.

Для оценки гендерного разрыва в социально-политических и экономических возможностях мужчин и женщин Всемирный экономический форум сконструировал и ежегодно рассчитывает специальный индекс, сопоставляющий ресурсы и реализованные возможности мужчин и женщин в 135 странах мира. Данный индекс фиксирует гендерный разрыв на основе 14 субиндексов, отражающих четыре аспекта. Два из них - образование и здоровье, сопоставляют параметры человеческого потенциала женщин и мужчин. Два других аспекта - экономические возможности и политические права измеряют успешность его фактической реализации. Человеческий потенциал в аспекте образования, оценивается по таким критериям, как грамотность населения, наличие и доступность образования различного уровня. Индекс здоровья и выживания строится на основе данных о продолжительности жизни мужчин и женщин и о соотношении полов при рождении.

При построении индекса гендерного неравенства в области экономической активности и экономических возможностей, учитываются такие параметры как уровень экономической активности, возможности доступа к престижным и хорошо оплачиваемым рабочим местам, а также соотношение заработных плат. В сфере политического права, индекс отражает долю представительства женщин в органах законодательной и исполнительной власти. Отчет по состоянию гендерного неравенства издается Всемирным экономическим форумом с 2006 г., но по ряду 
стран соответствующая информация собирается, уже начиная с 2000 г.

На протяжении двух десятилетий статус наиболее равноправных в гендерном отношении прочно удерживают страны северной Европы. Исландия, Финляндия, Норвегия и Швеция в период с 2000 по 2016 год делят между собой 4 первых места в списке. Заметим, что индексы лидирующих стран при итоговом подсчете увеличиваются в основном благодаря образовательному аспекту и высокому представительству женщин в структуре власти. Именно этим в немалой степени объясняется высокий рейтинг Филиппин: это одна из немногих стран мира, где доля женщин среди законодателей, высших чиновников и топ-менеджеров превышает долю мужчин. Наиболее ощутимый гендерный разрыв характерен для арабских стран: Саудовская Аравия. Россия занимает относительно устойчивое положение внизу верхней половины рейтинга, что свидетельствует о том, что у российских женщин, в сравнении с мужчинами, доступ к различным ресурсам ограничен, но не критичен.

Несмотря на общемировой тренд к сокращению гендерного разрыва, в ряде стран этот показатель вырос. Характерно, что в основном это восточноевропейские трансформационные экономики. Так, гендерный разрыв увеличили Хорватия, «упавшая» с 16 места до 49, Эстония с 29 места опустившаяся до 60, а также Македония, переместившаяся с 28 на 61 место. Несмотря на уменьшившуюся разницу в оплате труда мужчин и женщин, в Македонии показатель ухудшился за счет уменьшения политической активности женщин и крайне низкого субиндекса «здоровье и выживание» [1].

Среднемировые значения субиндексов образования и здоровья приближаются к единице, а во многих странах, к числу которых относится и Россия, разрыв по этим параметрам практически ликвидирован. Многие страны добились не только равенства в доступе к образованию, но и относительно более высоких показателей для женщин. Женский показатель уровня грамотности выше, чем у мужчин в 12 странах. Среди них преобладают страны Южной Америки и Африки. В развитых странах, где население практически поголовно грамотно, отрыв женщин по этому параметру невозможен. Однако многие из них демонстрируют более высокий по сравнению с мужчинами охват женщин высшим образованием. В Норвегии, Швеции и Исландии в высших учебных заведениях обучаются более $90 \%$ женщин соответствующего возраста, но лишь около половины мужчин. В Финляндии и Дании женщины также составляют большинство учащихся в высших учебных заведениях. Однако наибольший разрыв в пользу женщин по этому показателю демонстрирует Катар, где охват образованием женщин более чем в пять раз превышает охват мужчин. На Барбадосе женщины получают высшее образование примерно втрое чаще, чем мужчины.

При рассмотрении различных аспектов гендерного разрыва можно заметить, что отставание женщин от мужчин в том, что касается развития человеческого потенциала, преодолевается значительно активней, чем, когда речь идет о его реализации на рынке труда. Практически во всех странах мира женщины значительно менее успешны по сравнению с мужчинами. Это касается и уровня экономической активности женщин, и доступности для них хороших рабочих мест, и уровня оплаты труда. Следует отметить, что ряд сравнительно бедных стран с устойчиво низкими показателями экономической активности, занятости и оплаты труда (Монголия, Багамы, Бурунди) демонстрируют минимальный гендерный разрыв в области экономических возможностей. Иными словами, наивысшая степень гендерного равенства достигается в беднейших странах, где возможности эффективной экономической реализации человеческого потенциала крайне низки, как для мужчин, так и для женщин.

На иной основе достигается сближение экономических возможностей мужчин и женщин в странах Северной Европы, отличающихся высоким уровнем экономической активности и трудовых доходов большинства населения при минимальной разнице в параметрах занятости и оплаты труда по признаку пола. В этих странах созданы условия для того что бы в семье имели возможность работать оба родителя. Государство разработало гендерно нейтральную систему социальных гарантий, направленных на поддержку семьи, включающие единовременные выплаты при рождении ребенка, детские пособия, налоговые льготы для работодателей, у которых на производстве заняты работники с детьми, специальные программы поддержки материнства. Среди европейских стран самый высокий рейтинг преодоления гендерного разрыва имеют Норвегия и Люксембург. Россия по 
данному параметру занимает 39 место.

Таким образом «узким местом» на сегодняшний день является не недостаточное развитие человеческого потенциала женщин, а ограниченные возможности для его реализации. Данный вывод ВЭФ подтверждают результаты другого авторитетного международного исследования Программы развития ООН, в рамках которой разработана система индексов развития человеческого потенциала и ежегодно публикуются доклады, сопоставляющие параметры человеческого развития в различных странах мира. На протяжении нескольких лет в систему индексов развития человеческого потенциала ПРООН в качестве экспериментальной составляющей входит индекс гендерного неравенства. Страны-лидеры в области человеческого развития и в области преодоления гендерного разрыва отнюдь не всегда совпадают. Так, США, получившие в 2013 г. третий рейтинг по главному индексу развития человеческого потенциала, несмотря на всю риторику равноправия и продвижения женщин, по индексу гендерного неравенства занимают лишь 42 место. При этом наибольший вклад в гендерный разрыв вносят показатели участия в рабочей силе. Наибольший разрыв в пользу мужчин наблюдается в Арабском мире [2].

Данные международных исследований свидетельствуют также о том, что наращивание образовательного капитала далеко не всегда расширяет экономические возможности женщин. Неустойчивость положения женщин на рынке труда отражает их относительно низкий по сравнению с мужчинами уровень экономической активности. Эксперты Международной организации труда отмечают, что женщины в сравнении с мужчинами чаще заключают временные трудовые отношения, а также с тем, что женщина вынуждена прерывать свою карьеру ради воспитания детей. Во многих странах мира уровень женской безработицы превосходит уровень мужской [3]. Даже когда мужчины и женщины выходят на рынок труда, имея сопоставимый уровень квалификации, женщины, как правило, отстают при продвижении по карьерной лестнице. Женский труд преобладает на низших ступенях рынка труда, то есть на низкооплачиваемых, мало производительных работах, в том числе в неформальном секторе экономики [4].

Наиболее явно гендерные различия на рынке труда проявляются в существенном и устой- чивом отставании заработков женщин от заработков мужчин, которое имеет место во всех без исключения странах, даже наиболее эгалитарных. Как показывают данные мониторинга ВЭФ, охватывающего более сотни стран, вне зависимости от уровня экономического развития, заработки женщин всегда ниже чем мужчин. Разрыв составляет от $82 \%$ в Боливии, до всего 15\% в Сирии. И в такой бедной стране как Никарагуа, и в богатом благополучном Люксембурге, и в динамично развивающемся Сингапуре средний заработок женщин составляет примерно половину от заработка мужчин. В известной своими достижениями в области выравнивания возможностей Норвегии женщины зарабатывают менее 80\% от того, что зарабатывают мужчины [5].

Информационный портал «Экономика и общество» осуществил «инвентаризацию» доступной информации о гендерных различиях в оплате труда США - страны, где вопросы достижения гендерного равенства и поддержания «паритета» мужчин и женщин в сфере занятости, являются одним из первых государственных и общественных приоритетов. Отставание заработной платы женщин от заработной платы мужчин составляет от 23\% до 41\% в зависимости от сферы деятельности, а также расовой и этнической принадлежности. По данным Института исследований политик, направленных на женщин (Institute for Women's Policy Research), ведущего сопоставительный мониторинг женских и мужских заработков в США с 1955 г., разрыв заработков женщин и мужчин постепенно сокращается. Однако темпы этого сокращения очень медленные. При их сохранении по подсчетам сотрудников института паритет будет достигнут только к 2058 г. [6]. По данным Американской ассоциация женщин - выпускниц университетов, несмотря на то, что в процессе получения образования, успеваемость у женщин выше и они чаще повышают квалификацию после получения диплома, выпускницы, спустя год после окончания учебного заведения, зарабатывают в среднем на 20\% меньше мужчин. Спустя десять лет с момента выпуска, разница в доходе увеличивается до 31\% и появляется разрыв в должностном статусе. К тому моменту как женщина достигает возраста 65 лет, она зарабатывает, примерно 75\% от того, что зарабатывают мужчины того же возраста [7].

Проведенный анализ свидетельствует о том, что уязвимость женщин на рынке труда сегодня не может быть объяснена низким качеством жен- 
ской рабочей силы. В значительной степени она является следствием гендерной дискриминации, которая может существовать как в открытых, так и в замаскированных формах. Применительно к сфере занятости дискриминация означает, что к отдельным работникам, обладающим одинаковыми характеристиками по признаку производительности, относятся по-разному из-за того, что они представляют разные социально-демографические группы [8]. Можно выделить четыре пласта гендерной дискриминации, снижающие конкурентоспособность женщин на рынке труда. Первый пласт составляют дискриминационные практики вне сферы оплачиваемой занятости, отрицательно влияющие, прежде всего, на внутренние факторы конкурентоспособности женщин, связанные с качеством рабочей силы и с трудовой историей. Второй пласт - дискриминация при найме на работу, в процессе отбора работодателями претендентов на вакантные рабочие места. Третий - дискриминационные практики при должностных перемещениях и увольнениях. И наконец, дискриминационные практики, непосредственно связанные с оплатой труда.

Несмотря на постепенное распространение модернизационных ценностей, к числу которых относятся гендерное равенство и гендерная справедливость, и в обществе, и в исследовательской среде довольно прочные позиции удерживает подход, явно или неявно оправдывающий сохранение устоявшихся гендерных ролей. Его сторонники выстраивают различные системы аргументации, обосновывающие разделение труда между полами, в соответствии с которым естественное предназначение женщин быть хранительницами домашнего очага, а мужчин - кормильцами семьи, за которыми закрепляется роль первого работника. Апелляция к природным особенностям мужчин и женщин по существу представляет собой попытку закрепления в современной социально-экономической реальности дискриминационных практик, сложившихся на протяжении многих веков. Масштабное межстрановое исследование, проведенное в рамках ОЭСР, показало, что не только в странах третьего мира, но и в наиболее развитых экономиках значительная часть мужчин и женщин продолжают считаться с традиционными гендерными ролями. При этом их поведение, связанное с рынком труда, формируется под воздействием усвоенных ими культурных и социальных ценностей, которые как таковые носят дискриминационный характер и определяют те или иные черты образа жизни и трудового поведения как «мужские» или «женские» [9].

Второй пласт дискриминации женщин связан с неравным отношением к мужчинам и женщинам в процессе найма на работу, т.е. это дискриминация на открытом рынке труда. О предвзятом отношении к женщинам в процессе найма свидетельствуют обширные эмпирические данные. Ряд исследований показал, связанных в частности с распространением среди работодателей идентичных фиктивных резюме, подписанных мужскими и женскими именами, показал, что мужское имя существенно повышает шансы быть приглашенным на собеседование. При этом, если взаимосвязь между конкурентоспособностью работников мужчин и их семейным положением, в том числе наличием детей незначима, а иногда даже позитивна, то для женщин это очень серьезный негативный фактор, снижающий шансы получить работу [10].

Здесь следует сразу же заметить, что такого рода дискриминационные практики, к сожалению, основаны не только на стереотипах. Несмотря на то, что во многих странах, включая Россию, на отпуск по уходу за ребенком имеет право любой из родителей, на практике, в подавляющем большинстве случаев такими отпусками пользуются преимущественно женщины. Они же значительно чаще берут бюллетень в связи с болезнью детей. Словом, привлекательность женщин в глазах работодателей в значительной степени снижена в значительной степени именно благодаря реально существующему традиционному распределению гендерных ролей внутри семьи.

Укорененность традиционных гендерных установок лежит и в основе такой специфической формы гендерной дискриминации как горизонтальная сегрегация занятости, т.е. разделение профессий и видов экономической деятельности на «мужские» и «женские», т.е. дискриминация в доступе к определенным нишам рынка труда, как правило, характеризующимся относительно высоким уровнем заработков. Наряду с поиском компромисса между семьей и работой важным фактором, закрепляющим горизонтальную сегрегацию занятости, являются гендерные стереотипы. Во многом именно благодаря стереотипам доминирует тенденция преобладания женщин в тех сферах занятости, 
которые предполагают выполнение «естественных» для женщин функций: воспитания детей, заботы о здоровье и благополучии близких, ухода за теми, кто не может обслуживать себя сам. В результате многие женщины склонны отдавать предпочтение занятости в так называемой «мягкой экономике», т.е. в таких сферах деятельности как образование, здравоохранение, сфера услуг [11]. Таким образом поддерживается неявный социальный контракт, предопределяющий как разные предпочтения работников в отношении тех или иных видов деятельности и разное отношение работодателей в зависимости от того, претендует ли тот или иной соискатель на место в мужском или женском сегменте рынка труда.

Гендерная дискриминация женщин на рынке труда не исчерпывается горизонтальной сегрегацией, обусловливающей концентрацию женского труда в относительно низко оплачиваемых видах деятельности. Не менее важным ее проявлением является вертикальная сегрегация, закрепляющая различия в должностном положении мужчин и женщин. Для объяснения феномена вертикальной сегрегации обычно используется введенная в научный оборот в 80-х годах прошлого века метафора «стеклянного потолка». Она фиксирует тот факт, что, несмотря на юридическое закрепление принципа равных возможностей, на практике существует множество неформальных, «невидимых» барьеров, препятствующих продвижению женщин по ступеням должностной иерархии и не позволяющих им продвинуться выше определенного уровня.

Наконец последний четвертый пласт дискриминации, связан с прямой дискриминацией в оплате труда. Как было показано выше, отставание заработков женщин от заработков мужчин отмечается во всех без исключения странах, где проводились соответствующие замеры. Гендерный разрыв в оплате труда является важнейшим количественным индикатором относительно более низкой конкурентоспособности женщин. Разрыв в оплате труда также может быть следствием разных факторов. Наиболее очевидный из них - меньшая продолжительность рабочего времени. Кроме того, мужчины чаще женщин работают в тяжелых и опасных условиях, что предполагает соответствующую компенсацию, а женщины чаще имеют перерывы в работе и силу различия планки пенсионного возраста раньше заканчивают карьеру.

Следует отметить, что многие из перечисленных факторов, на первый взгляд прямо не связанных с дискриминацией, тем не менее могут являться следствием более широких проявлений дискриминации, лежащих вне сферы занятости.

Таким образом, более слабые позиции женщин на рынке труда, являющееся свидетельством их относительно низкой конкурентоспособности по сравнению с мужчинами, могут представлять собой как следствие дискриминационных практик, имевших или имеющих место вне этой сферы, так и дискриминацию в чистом виде. При этом довольно сложно отделить одно от другого. Укорененность традиционных гендерных ролей образует своеобразный порочный круг: обремененность домашними обязанностями не дает женщинам в достаточной мере реализоваться в профессиональной деятельности, следствием чего является относительно низкая оплата их труда. А она, в свою очередь, служит аргументом для окончательного закрепления их в традиционной социальной роли.

\section{Библиографический список}

1. The Global Gender Gap Report 2017. World Economic Forum. Geneva, 2017 http://www3.weforum.org/docs/WEF_ GGGR_2017.pdf (дата обращения 12.08.2018)

2. Цели развития тысячелетия: доклад за 2015 год. Нью-Йорк. ПРОOH, 2012. URL: http://www.un.org/ru/ millenniumgoals/mdgreport2015.pdf (дата обращения 12.08.2018)

3. ILO. Global Employment Trends for Women: December 2012 / International Labour Office. - Geneva: ILO, 2012.

4. Содействие переходу к формальной экономике на примере некоторых государств - участников СНГ / Под ред. О. Кулаевой и Ф. Лапера.- М.: МОТ. 2014.

5. The Global Gender Gap Report 2017. World Economic Forum. Geneva. 2017 http://www3.weforum.org/docs/WEF_ GGGR_2017.pdf (дата обращения 12.08.2018)

6. Hegewisch A., Williams C., Hartmann H., Hudiburg S. The Gender Wage Gap: 2013. Differences by Race and Ethnicity. No Growth in Real Wages for Women. 2014. URL: https://www.coursehero.com/file/p2nod2i/The-Gender-WageGap-2013-Differences-by-Race-and-Ethnicity-No-Growth-in-Real/ (дата обращения 12.08.2018) 
7. The Simple Truth about the Gender Pay Gap. American Association of University Women Educational Foundation/ Washington, DC. 2018 URL: https://www.aauw.org/aauw_check/pdf_download/show_pdf.php?file=The_Simple_ Truth (дата обращения 12.08.2018)

8. Воронина О.А. Формирование гендерного подхода в социальных науках / Гендерный калейдоскоп. Москва. 2001. C. 4-14.

9. Баскакова М.Е., Мезенщева Е.Б. Гендерное преломление целей развития тысячелетия для России / Народонаселение. 2006. № 1. С. 43-58.

10. Goldin C., Rouse C. Orchestrating Impartiality: The Impact of 'Blind' Auditions on Female Musicians // American Economic Review. 1997. T. 90. № 4. P. 715-742.

11. Esping-Andersen G. Why We Need a New Welfare State. Oxford: Oxford University Press, 2002.

Поступила в редакцию 25.09.2018 